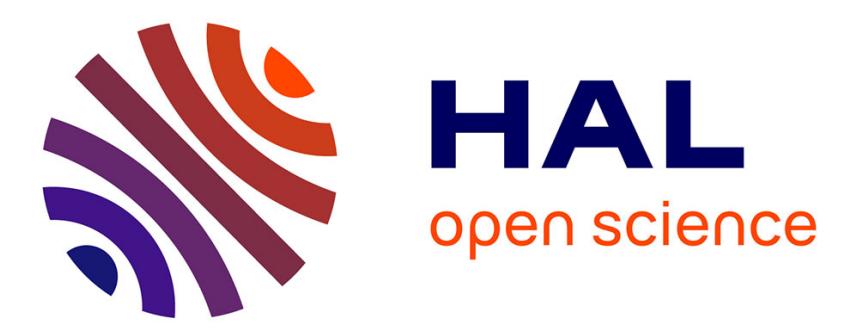

\title{
Habitat fragmentation and food security in crop pollination systems
}

\author{
Daniel Montoya, Bart Haegeman, Sabrina Gaba, Claire de Mazancourt, \\ Michel Loreau
}

\section{- To cite this version:}

Daniel Montoya, Bart Haegeman, Sabrina Gaba, Claire de Mazancourt, Michel Loreau. Habitat fragmentation and food security in crop pollination systems. Journal of Ecology, 2021, 109 (8), pp.2991-3006. 10.1111/1365-2745.13713 . hal-03295896v2

\section{HAL Id: hal-03295896 https://hal.science/hal-03295896v2}

Submitted on 20 Oct 2021

HAL is a multi-disciplinary open access archive for the deposit and dissemination of scientific research documents, whether they are published or not. The documents may come from teaching and research institutions in France or abroad, or from public or private research centers.
L'archive ouverte pluridisciplinaire HAL, est destinée au dépôt et à la diffusion de documents scientifiques de niveau recherche, publiés ou non, émanant des établissements d'enseignement et de recherche français ou étrangers, des laboratoires publics ou privés. 
Daniel Montoya ${ }^{1,2,3}$, Bart Haegeman ${ }^{3}$, Sabrina Gaba ${ }^{4,5}$, Claire De Mazancourt ${ }^{3}$ \&

${ }^{1}$ Basque Centre for Climate Change (BC3), Edificio Sede 1, Planta 1, Parque Científico UPV-EHU, Barrio Sarriena, Leioa, Spain

${ }^{2}$ IKERBASQUE, Basque Foundation for Science, Bilbao, Spain

${ }^{3}$ Centre for Biodiversity Theory and Modelling, Theoretical and Experimental Ecology Station, UMR 5321, CNRS, 09200 Moulis, France

${ }^{4}$ USC 1339, Centre d'Etudes Biologiques de Chizé, INRAE, 79360 Villiers en Bois, 19 France

$20{ }^{5}$ Centre d'Etudes Biologiques de Chizé, UMR 7372, CNRS \& Université de La Rochelle, 79360 Villiers en Bois, France

22

Author for correspondence:

Daniel Montoya, (daniel.montoya@sete.cnrs.fr)

Tel: $(+33)(0) 673360487$

27 Centre for Biodiversity Theory and Modelling, Theoretical and Experimental Ecology

Station, CNRS, 2 route du CNRS, 09200 Moulis, France

29

30

Word count: Abstract: 347; Main text: 5992; References: 75; Figures: 5; Tables: 1 


\section{Abstract}

1. Ensuring stable food supplies is a major challenge for the $21^{\text {st }}$ century. There is consensus that increased food production is necessary, but not sufficient, to achieve food security, and that agriculture should also aim at stabilizing crop production over time. In this context, biodiversity-based approaches to food security are increasingly being supported based on the fact that biodiversity can increase and stabilize crop production. However, agricultural systems are often highly fragmented and our current understanding of how such fragmentation affects biodiversity and food production remains incomplete, thus limiting our capacity to manage agricultural landscapes for food security.

2. We developed a spatially-explicit model of crop dynamics to investigate how the fragmentation of natural habitats for agricultural conversion impacts food production and food security, with a focus on animal-dependent crop production.

3. Fragmentation produces a variety of spatial and biodiversity-mediated effects that affect both the mean and stability (temporal invariability) of animal-dependent crop production.

4. Fragmentation has a dual effect on animal-dependent production. On one hand, spatial aggregation of natural land decreases animal-dependent production by reducing the Landscape Pollination Potential, a metric that captures fragmentation and pollinator spillover effects within the agricultural landscape. But aggregation increases animaldependent production by maintaining a higher pollinator diversity in larger fragments of natural habitat. The net effects of fragmentation on animal-dependent crop production depend on the land-use change pattern, the strength of the pollinator spillover to crop land and the animal pollination-dependence of crops.

5. Synthesis. Our study sheds new light in the food security debate by showing that high 
57 and stable crop production depends on biodiversity and the spatial fragmentation of

58 agricultural landscapes, and by revealing the ecological mechanisms of food security

59 in crop pollination systems. Management for food security should consider factors

60 such as pollinators' spillover, the amount and spatial aggregation of seminatural habitat

61 and the animal pollination-dependence of crops. This information would be useful to

62 design agricultural landscapes for high Landscape Pollination Potential. These results

63 are highly relevant in the global change context, and given the worldwide trends in

64 agriculture, which shifts towards more animal-dependent crop production.

65

66 Keywords: Habitat fragmentation, pollination, biodiversity, food security, stability,

67 ecosystem services, global change 
70 Ensuring stable food supplies for a growing population is one of the UN Sustainable

71 Development Goals (UN2017). Biodiversity-based approaches to food security suggest

72 that safeguarding species diversity is fundamental to increase yields and guarantee stable

73 yields. This is supported by theory and data reporting positive effects of biodiversity on

74 the mean values of various ecosystem functions and services, such as biomass production,

75 nutrient cycling and crop pollination (Lefcheck et al. 2015; Woodcock 2019).

76 Additionally, biodiversity can stabilize ecosystem service supply by providing an

77 insurance against environmental fluctuations (Loreau et al. 2003), which are predicted to

78 intensify under global change (Giorgi et al. 2001; Saltz et al. 2006; Fischer et al. 2013).

79 Biodiversity insurance effects have been observed in agriculture, where a greater

80 diversity of crops is associated with increased year-to-year temporal stability of total

81 production (Winfree \& Kremen 2009; Renard \& Tilman 2019). However, most

82 biodiversity in intensively-managed agricultural landscapes is found in the remaining

83 fragments of (semi)natural habitat not converted into crop land, and the effects of such

84 non-crop biodiversity on the provision and stability of crop production are not clearly

85 understood. This has led to a growing concern over the large-scale conversion of natural

86 habitats into crop land and their effects on biodiversity and food production (Godfray \&

87 Garnett 2014; UN2017; Réchauchère et al. 2018).

88

89 Agricultural systems are often highly fragmented with areas of intensive cultivation

90 interspersed among remnant patches of seminatural habitat. This loss and fragmentation

91 negatively affect biodiversity and many ecosystem functions and services (Haddad et al.

92 2015; Rybicki et al. 2020). Despite this, fragments of natural habitat continue to supply 
93 important services. The spatial coexistence of crops and natural land creates an 94 opportunity for spillover effects (Rand et al. 2006), a situation where ecological

95 interactions extend across habitats boundaries and propagate ecological functions. In

96 some cases, fragmentation can increase ecosystem service supply (Martin et al. 2019;

97 Haan et al. 2020), e.g. if fragmentation of natural habitat for pollinators optimizes

98 interspersion with crop land to maximize crop pollination (Brosi et al. 2008). But

99 fragmentation can also reduce ecosystem service supply if biodiversity decreases

100 significantly in the remnant fragments of natural habitat (Haddad et al. 2015). For most

101 services, however, we do not know how fragmentation affects their provision in

102 fragmented landscapes, and this limits our capacity to manage biodiversity-based

103 ecosystem service provision, e.g. crop pollination, and food security in human-dominated 104 landscapes.

106 Recent research has revealed strong, non-linear effects of land-use change on crop 107 production at multiple spatial scales. For example, theoretical studies agree on the hump108 shaped relationship between animal pollination-dependent crop production and the 109 fraction of remnant natural land within intensive farming systems (Braat \& ten Brink 110 2008; Mitchell et al. 2015; Montoya et al. 2019). Empirical research on the stability of

111 animal pollination dependent crop production shows that stability decreases with 112 agricultural intensification and the degree to which crops depend on animal pollination

113 (Garibaldi et al. 2011a, b, 2014; Deguines et al. 2014). Changes in crop production 114 stability of animal-pollinated crops also depend on the spatial composition and structure 115 of agricultural landscapes, such as the amount of natural land cover (Montoya et al. 2019)

116 and the isolation of crops from natural land (Garibaldi et al. 2011b). Overall, both 117 theoretical and empirical studies suggest that improved management of agricultural 
118 landscapes should increase the amount and stability of animal pollination-dependent crop 119 production, and that an understanding of how the spatial pattern of land-use change 120 fragmentation - impacts ecosystem services is key to achieve this goal. However, none 121 of these studies have simultaneously combined crop dynamics at different scales and

122 spatially-explicit landscapes to investigate the effects of land-use change on biodiversity

123 and crop production services. Further, while multiple factors can influence crop 124 production in fragmented agroecosystems, our current understanding of how they interact 125 and determine crop production stability, and thus food security, remains incomplete.

127 There is general consensus that increased food production is necessary, but not sufficient, 128 to achieve food security (Godfray \& Garnett 2014), and that agriculture, especially in the 129 global change context, should also aim at stabilizing crop production over time 130 (Schmidhuber \& Tubiello 2007; Montoya et al. 2020). Bearing this in mind, we here 131 extend a model of crop dynamics into a spatially-explicit landscape to investigate how 132 habitat loss and fragmentation, i.e. the amount and spatial configuration of seminatural 133 habitat, influence the mean provision and stability of crop production in agricultural 134 landscapes. We focus on animal-dependent crop production because (i) animal crop 135 pollination is a key agricultural service that depends on biodiversity (pollinator animals), 136 and (ii) worldwide agriculture is shifting towards more animal pollination-dependent 137 food production systems (Aizen et al. 2009; Breeze et al. 2014). Because the way food is 138 produced worldwide threatens the existence of much of the world's biodiversity that 139 contributes to crop pollination and food security, we explore how changes in biodiversity 140 following land-use change affect animal-dependent crop production in fragmented 141 agroecosystems. Thus, our model accounts for a variety of potential drivers of crop 142 production mean and stability, such as loss and fragmentation of natural habitat and 
143 biodiversity, that are difficult to address collectively in empirical studies. Specifically,

144 we address two questions: (i) How does the spatial pattern of land-use change influence

145 the provision and stability of animal -dependent crop production in agroecosystems? (ii)

146 How does biodiversity in fragmented landscapes influence animal-dependent crop

147 production and food security?

\section{Materials and Methods}

151 To study the effects of habitat fragmentation on biodiversity and crop production, we

152 extended a non-spatial model of crop dynamics (Montoya et al. 2019) to a spatially153 explicit landscape. Our model has two types of patches: crop land and seminatural habitat.

154 Crop land is used to grow annual crops with varying degrees of dependence on animal 155 pollination, whereas seminatural habitat shelters biodiversity, including 'wild' plants and 156 pollinators. The model does not consider managed honeybees as they do not depend on 157 seminatural habitat for nesting, and generally pollinate less efficiently than non-managed 158 pollinators (Garibaldi et al. 2013). Naturalized Apis species are implicitly considered in 159 the model as they nest in seminatural habitat and forage across the landscape. This model 160 represents intensively-managed agricultural systems, where crop land does not host significant levels of biodiversity, and spatial heterogeneity is broadly defined by two 162 patch types.

164 The model investigates the expected biodiversity (i.e. species richness) and crop 165 production, with a special focus on animal-dependent crop production, at the farm- (i.e. crop yield per area) and landscape-levels (i.e. the magnitude and stability of crop

167 production). We distinguish between two additive ecosystem services associated with 
crop production: the production that results from wild animal pollination (hereafter animal-dependent production), and the production that is independent from animal pollination (animal-independent production), but can be wind- or self-pollinated.

171 Pollinators are assumed to be generalist central-place foragers that nest in seminatural

172 habitat (Gill et al. 2016), yet move across the landscape to forage on either flowering

173 crops or 'wild' plants, or both. Crop land and seminatural habitat are therefore linked by 174 the pollinators' foraging movement. For simplicity, the model assumes similar foraging 175 movements across pollinators. The main difference between the non-spatial and spatial 176 models lies on the way pollinators link these two patch types: whereas in the non-spatial 177 model pollinators move globally and reach all crop land, the spatial model imposes

178 restrictions to pollinator's movement based on the spatial structure of the agricultural 179 landscape (i.e. distribution of crop land and seminatural habitat) and the foraging range of pollinators (i.e. spillover). A conceptual representation of the model, including nonspatial and spatial components, as well as key model assumptions, is provided in Fig. 1.

182 In what follows, we first describe the spatial agroecosystem model and then present a

183 simpler, mean-field approximation of the model that we use to produce the results.

\section{Spatial agroecosystem model}

186 The addition of space allows: (i) to explore a continuous gradient of land-use change

187 patterns, from completely random to highly aggregated, that encompasses a wide range

188 of fragmentation scenarios, (ii) to investigate the effects of fragmentation on pollinator diversity and crop production services, and (iii) to study how variations in the strength of spillover from seminatural habitat to crop land - i.e. the distance-decay of pollination

191 flow - affects animal-dependent crop production. To do this, we simulated a continuous 192 gradient of land-use change patterns, and therefore fragmentation, based on the 
aggregation degree of seminatural habitat. A complete description of the model parameters can be found in Table 1. Information on model parameterization is in Appendix S1.

197 Landscape pattern generation. The landscape consisted of a two-dimensional lattice $198(25 \times 25$ cells $)$ where individual cells can have either of two states: crop land or seminatural habitat. We generated land-use change patterns by iteratively creating crop land cells in a landscape that consisted initially only of seminatural land. In a single step of the algorithm only one semi-natural habitat cell is selected and converted. The pattern generation is controlled by a parameter $w$ that determines the clustering degree of the land-use change pattern (see Appendix S1). Hence, for $w=0$ all seminatural land cells had the same relative probability to be chosen, leading to a fully random, unclustered pattern. Larger values of $w$ resulted in more aggregated patterns. Therefore, variation in the value of $w$ allowed us to produce a continuous gradient of land-use change patterns, and therefore

207 fragmentation, based on the aggregation degree. For each land-use change pattern, we 208 characterised fragmentation of the remaining seminatural habitat by quantifying mean 209 fragment size, number of fragments, mean fragment perimeter, and perimeter: area ratio. 210 Fragmentation directly affects pollinator diversity (through the estimation of the 211 metapopulation capacity) and the Landscape Pollination Potential (LPP), which in turn 212 influence crop production services (see below).

214 General model dynamics. Pollinators, 'wild' plants and crop production are represented 215 by Equations 1-3. In these equations, the first term defines growth and is modelled using 216 the discrete Ricker equation, whereas the second and third terms add environmental and 217 demographic stochasticity to the model: 
$P_{k}(t+1)=P_{k}(t) \exp \left(r_{P, k}(t)\left(1-\frac{P_{k}(t)}{k_{P} A_{1}}\right)\right)+\sigma_{P}^{e} u_{P}^{e}(t) P_{k}(t)+\frac{\sigma_{P}^{d} u_{P}^{d}(t)}{\sqrt{P_{k}(t)}} P_{k}(t)$

220

$W_{k}(t+1)=W_{k}(t) \exp \left(r_{W, k}(t)\left(1-\frac{W_{k}(t)}{k_{W} A_{1}}\right)\right)+\sigma_{W}^{e} u_{W}^{e}(t) W_{k}(t)+\frac{\sigma_{W}^{d} u_{W}^{d}(t)}{\sqrt{W_{k}(t)}} W_{k}(t)$

221

$C_{k}(t)=A_{1}\left[Z_{C}+r_{C, k}(t)\right]\left(1+\sigma_{C}^{e} u_{C}^{e}(t)\right)$

$223 P_{k}$ represents pollinators, $W_{k}$ 'wild' plants and $C_{k}$ crop production in cell $k$, with $P_{k}(t)=$ $W_{k}(t)=0$ if $k$ is a crop land cell, and $C_{k}(t)=0$ if $k$ is seminatural habitat. One unit of time $t$ corresponds to one growing season, $P(t)$ and $W(t)$ can be interpreted as total biomass of pollinators and 'wild' plants over growth season $t$, respectively, whereas $C(t)$ is the total crop production at the end of the growing season $t . r_{P, k}(t), r_{W, k}(t), r_{C, k}(t)$ are the pollinators', 'wild' plants' and crop's per capita growth rates. $Z_{C}$ is the crop production independent of animal pollination, which allows varying degrees of animal-dependence production. $C_{k}$ is thus the sum of animal-dependent and -independent parts of crop production. $k_{P}$ and $k_{W}$ are the carrying capacities of pollinators and 'wild' plants, respectively, per unit area. $A_{1}$ is the area of a single cell; $A$ is total landscape area; $A[1-$ $\left.\omega_{s n}\right]$ is the total crop land area, and $A \omega_{s n}$ is total seminatural area. In the non-spatial model, $k$ and $A_{1}$ were not defined. Stochasticity is included in the form of $\sigma u(t)$, where $\sigma^{2}$ is the variance (environmental or ${ }^{\mathrm{d}}$ demographic) and $u(t)$ are independent Gaussian random variables with zero mean and unit variance, of either pollinators $\left(\sigma_{P} u_{P}\right)$, 'wild' plants $\left(\sigma_{W u_{W}}\right)$ or crops $\left(\sigma_{C} u_{C}\right)$ (see model stochasticity section below).

239 Growth rate of pollinators and plants. Since pollinators are assumed to be generalist central-place foragers, pollinator's growth rate depends on the availability of resources 
as well as the animal-dependent crop production, follow a saturating, type II functional response, widely supported and consistent with real biological examples (Thebault \&

244 Fontaine 2010; Holland et al. 2013; Holland 2015). Growth rates are thus defined by the 245 following Monod/Michaelis-Menten equations:

$247 \quad r_{P, k}(t)=\frac{\alpha_{P}\left[\frac{\sum_{l \notin L} \varepsilon_{k l} W_{l}(t)+\sum_{l \in L} \varepsilon_{k l} C_{l}(t)}{A}\right]}{\beta_{P}+\frac{\sum_{l \notin L} \varepsilon_{k l} W_{l}(t)+\sum_{l \in L} \varepsilon_{k l} C_{l}(t)}{A}}$

$248 \quad r_{W, k}(t)=\frac{\alpha_{W}\left(\frac{\sum_{l \notin L} \varepsilon_{k l} P_{l}(t)}{A}\right)}{\beta_{W}+\frac{\Sigma_{l \notin L} \varepsilon_{k l} P_{l}(t)}{A}}$

249

$r_{C, k}(t)=\frac{\alpha_{C}\left[\frac{\sum_{l \notin L} \varepsilon_{k l} P_{l}(t)}{A}\right]}{\beta_{C}+\frac{\sum_{l \notin L} \varepsilon_{k l} P_{l}(t)}{A}}$

, where $\varepsilon_{k l}$ is the distance-decay function representing the decrease of ecosystem service flow from seminatural habitat to crop land (i.e. spillover effects, see below); $L$ is the set of crop land cells; $\alpha_{P}$ and $\alpha_{W}$ are the maximum growth rates of pollinators and 'wild' plants, respectively; $\beta_{P}$ and $\beta_{W}$ are half-saturation constants of pollinators and 'wild' plants, respectively; $\alpha_{C}$ is the maximum crop production derived from pollination, and $\beta_{C}$ is the half-saturation constant of crops.

Because crops vary in their dependency on animal pollination, different crop types can respond differently to landscape fragmentation. In our model, the degree to which crops depend on animal pollination is measured by $\alpha_{C} /\left(Z_{C}+\alpha_{C}\right)$, and reflects the part of total

261 crop production dependent on animal pollination - i.e. animal-dependent production.

262 Landscape crop production is estimated by summing up the individual contribution of each cell $k$. Thus, for total crop production we obtained $C(t)=\sum_{k \in L} C_{k}(t)$. We assume that crops are harvested yearly; hence, mean crop production represents the temporal 
mean of the yearly averaged crop production across the agricultural landscape. Crop yield per unit of agricultural area is calculated by dividing total crop production by crop land area.

Model stochasticity. To investigate the effects of fragmentation on crop production stability, the model includes environmental and demographic stochasticity (second and third terms, Eqs. 1-3). Stochasticity is included in the form of $\sigma u(t)$, where $\sigma^{2}$ is the variance and $u(t)$ are independent Gaussian random variables with zero mean and unit variance, of either pollinators $\left(\sigma_{P} u_{P}\right)$, 'wild' plants $\left(\sigma_{W} u_{W}\right)$ or crops $\left(\sigma_{C} u_{C}\right)$. Environmental stochasticity $\left(\sigma^{e} u^{e}(t)\right)$ reflects variation in weather variables, e.g. temperature and rainfall, whereas demographic stochasticity $\left(\sigma^{d} u^{d}(t)\right)$ emerges from stochastic variation in individuals' births and deaths, commonly observed in nature and important in small

277 populations. Crops are sown at high densities, and thus we assume demographic stochasticity is prevented in crops. These two sources of stochasticity add biological realism to the model, as they allow variation in the biomass of pollinators, 'wild' plants and crops, useful to assess stability. We used $1 / \mathrm{CV}^{2}$ as a metric of stability (invariability), where $\mathrm{CV}$ is the temporal coefficient of variation of crop production. This measure of stability is commonly used in ecological studies (Loreau \& De Mazancourt 2013).

Distance-decay of pollinators (spillover effects). The spatially-explicit nature of the model allows to study how variations in the strength of spillover effects influences crop pollination. Ecosystem service distance-decay $\left(\varepsilon_{k l}\right)$ affects the flow of pollination to crop land: the further crops are from seminatural habitat, the more difficult it is for pollinators to reach the crops, and thus the smaller the effect of pollinators on crop production. To model spillover effects, we used a logistic distance-decay function adapted from Mitchell 
et al. (2015) (Appendix S1). This function is consistent with both theoretical predictions

291 (Ries et al. 2004; Rand et al. 2006; Ricketts et al. 2008) and empirical observations

292 (Farwig et al. 2009; Mitchell et al. 2014; Martins et al. 2015) of the effects of habitat

293 edges and distance-to-habitat fragment gradients on ecosystem service provision. The

294 logistic distance-decay function has two parameters: (i) the distance from seminatural cell

295 edge at which the pollination flow equals one half of its initial value $-50 \%$ decay distance

$296-\left(d_{m}\right)$, and (ii) the distance over which the pollination flow decreases from $90 \%$ to $10 \%$

297 of its initial value $-90 \%$ to $10 \%$ decay distance $(\Delta d)$.

298

299 Fragmentation, biodiversity and crop pollination. To consider the effects of

300 fragmentation on biodiversity and crop production, we included two relationships in our

model: (i) the dependence of pollinator diversity on the amount and distribution of seminatural habitat, and (ii) the dependence of crop production on pollinator diversity. In the first case, we used the Species-Fragmented Area Relationship (SFAR; Hanski et al. 2013), which extends one of the oldest known and most documented patterns in ecology - the species-area relationship (SAR) - to fragmented landscapes. Despite recent debate has ensued on the relative importance of habitat loss versus fragmentation on species

307 diversity (Rybicki et al. 2020; Fletcher et al. 2018; Fahrig et al. 2018), empirical evidence

308 shows that larger and more connected fragments of natural habitat in general host more 309 biodiversity than smaller, more isolated fragments (Haddad et al. 2015). In agricultural 310 landscapes, this means that different fragmentation patterns will affect biodiversity and crop production in different ways. In an agricultural landscape, the SFAR can be modeled

312 as a power law: $S=c_{S}\left(A \omega_{s n}\right)^{z_{S}}$, where $S$ is pollinator diversity, $A \omega_{s n}$ is the total area of 313 seminatural habitat, and $z_{s}$ is the power-law exponent. The prefactor $c_{S}$ is not a constant 
314 as in the standard SAR; rather, it decreases in more fragmented landscapes (see Appendix

315 S1 for more details).

317 For the second relationship - the dependency between crop production and pollinator 318 diversity -, we created a dependence of pollinator's carrying capacity $\left(k_{P}\right)$ on biodiversity

319 following a power law: $k_{P}=c_{P} S^{Z_{P}}$, where $S$ is the number of pollinator species estimated 320 by the SFAR, and $c_{P}, z_{P}$ are parameters of the power law (Liang et al. 2016; O'Connor 321 et al. 2017). Although pollinators can differ in their pollination efficiency (Matsuki et al. 322 2008; Kleijn et al. 2015; Willcox et al. 2017), such differences do not dilute the positive 323 relationship between pollinator diversity and crop production and yield, as reported in 324 meta-analytical studies (Woodcock et al. 2019). Additionally, we considered the ability 325 of pollinator diversity to provide an insurance against environmental fluctuations.

326 Following the biodiversity insurance hypothesis (Loreau et al. 2003), pollinator diversity 327 insures crop production because many pollinators better maintain crop production if 328 pollinators differ in their responses to environmental variation. We followed the 329 ecological literature and made pollinators' environmental stochasticity inversely related 330 to their diversity $\left(\sigma_{P}^{e}=e_{P} / S^{q}\right.$; Tilman 1999). Demographic stochasticity acts at the 331 individual level, and in the same manner for conspecifics and heterospecifics; thus, there 332 is no insurance effect for demographic stochasticity.

334 Non-spatial model results: summary

335 The relationship between mean crop production and the proportion of seminatural habitat 336 is hump-shaped, and the height and position of the hump depends on crop pollination 337 dependence $\left(\alpha_{C} /\left(Z_{C}+\alpha_{C}\right)\right)$ and the crop relative requirement for pollinator densities $\left(\beta_{C} / k_{P}\right)$ 338 (Fig. S1; Montoya et al. 2019). Higher and lower values of these factors, respectively, 
339 shift maximum production to higher fractions of seminatural habitat. On the other hand,

340 the stability of animal-dependent crop production is generally an increasing function of

341 proportion of seminatural habitat and is also determined by the same factors: higher crop

342 pollination dependence and crop relative requirement for pollinators decreases stability.

344 Mean-field approximation of the spatial model

345 Given the computational demands of the model, we developed a mean-field approximation which replaces the detailed spatial flows between seminatural habitat and

347 crop land cells by their values spatially-averaged over the landscape. More precisely, we

348 substituted the pollination flow decay coefficients (Eqs. 4-6) by the average $\bar{\varepsilon}$ (i.e. the average value of $\varepsilon_{k l}$ when taking a random cell $k \in L$ and a random cell $\left.l \notin L\right)$ :

350

351

$\bar{\varepsilon}=\frac{1}{\left(1-\omega_{s n}\right) n^{2}} \frac{1}{\omega_{s n} n^{2}} \sum_{k \in L, l \notin L} \varepsilon_{k l}$

352

353 This quantity has two complementary interpretations (see Appendix S2 for the derivation). First, it is the fraction of seminatural habitat from which a crop land cell can be pollinated, averaged over all crop land cells. Second, it is the fraction of crop land that is reachable by pollinators from a seminatural habitat cell, averaged over all seminatural cells. Taken together, these two interpretations can be summarized by the term Landscape Pollination Potential or LPP (LPP replaces $\bar{\varepsilon}$ hereafter; $0 \leq \mathrm{LPP} \leq 1$ ).

360 The mean-field approximation is a very accurate description of the ecosystem service

361 dynamics in agricultural landscapes (Fig. 2; Appendix S2), and shows that the spatial

362 effects of fragmentation on animal-dependent crop production are determined by LPP.

363 Thus, LPP is a metric that captures fragmentation and pollinator spillover effects within 
364 agricultural landscapes. To consider the spatial structure of land-use change, the term $365 \beta_{C} / k_{P}$ of the non-spatial model must be replaced by

$366 \frac{1}{L P P} \frac{\beta_{C}}{k_{P}}$

367 where $\beta_{C} / k_{P}$ is the crop relative requirement for pollinators (described above).

\section{Results}

371 The results here presented correspond to the mean-field approximation, as it provides a

372 very accurate description of the model dynamics (Fig. 2). We present three groups of 373 results: (i-ii) the effects of LPP and biodiversity on crop production, and (iii) the net 374 effects of fragmentation on animal-dependent production.

375

\section{Effects of LPP on crop production}

377 When LPP $=1$, fragmentation effects are negligible and crop dynamics are identical to 378 those of the non-spatial model (Fig. 3A-C, dark-blue lines). In this case, we retrieve the 379 same mechanisms of the non-spatial model (Montoya et al. 2019). The effects of 380 fragmentation kick off when LPP $<1$. Lower LPP reduces the carrying capacity of 381 pollinators effectively; that is, the effects of LPP on the mean and stability of crop 382 production can be fully taken into account by changing the value of the pollinators' 383 carrying capacity from $k_{P}$ to $\mathrm{LPP}^{*} k_{P}$ (Eq. 8). LPP-driven reduction in pollinators' 384 carrying capacity decreases the mean provision of animal-dependent production (Fig. 3A) and crop yield per area (crop yield per area increases with seminatural habitat, but larger LPP saturates this relationship earlier; Fig. 3C). The same is true for the stability of animal-dependent production, except at small fractions of seminatural habitat and/or small values of LPP (Fig. 3B). LPP has no effect on animal-independent crop production 
as it does not depend on animal pollination and, therefore, on seminatural habitat; its mean value decreases linearly with seminatural habitat, whereas its stability is solely determined by environmental stochasticity (Fig. 3D-E). Because of this, animalindependent crop production is not further considered in subsequent results. Whereas the

393 full complexity of the spatial fragmentation effects (i.e. those not mediated by 394 biodiversity) on animal-dependent production are captured by LPP (Fig. S2), we did not 395 find any clear, consistent effect of specific fragmentation metrics (Fig. S3), except for 'Number of crop land cells $>$ distance threshold'. This is because the latter variable uses distance-decay parameter $d_{m}$ as the reference threshold, and it is thus correlated with LPP. However, the dependence of both metrics on $d_{m}$ does not really explain their correlation: LPP measures the fraction of crop land within a distance $d_{m}$ of seminatural habitat and quantifies the interspersion of seminatural habitat and crop land at the scale of the pollination spillover distance $d_{m}$, thus capturing an important dimension of fragmentation (i.e. interspersion) that is not or poorly considered by the standard fragmentation metrics.

403 Finally, the effect of LPP on animal-dependent production increases with the degree to 404 which crops depend on animal pollination: higher pollination dependence shifts maximum production to higher fractions of seminatural habitat at landscape and local scales, and the stability of animal-dependent production increases faster (Fig. S4), consistent with Montoya et al. (2019).

409 LPP depends on two factors: fragmentation and spillover, or the distance-decay of 410 ecosystem service flow. High aggregation (low fragmentation) and fast distance-decay 411 result in lower LPP $(\mathrm{LPP}<1)$, which in turn reduces animal-dependent crop production.

412 These two factors interact: only when the flow of pollinators to crop land is limited (fast 413 distance-decay) aggregation patterns influence animal-dependent production. When no 
414 restrictions exist in the flow of pollinators to crop land, LPP is maximum and

415 fragmentation does not affect animal-dependent production $($ LPP $\approx 1)$.

416

\section{Effects of biodiversity on crop production}

418 In parallel to LPP, pollinator diversity also impacts animal-dependent crop production.

419 As expected, biodiversity enhances animal-dependent production at local (i.e. yield per 420 area) and landscape scales (Fig. 4A, C), and stabilizes animal-dependent production (Fig.

421 4B) by increasing the pollinators' carrying capacity, and by reducing the response of

422 animal-dependent production to environmental fluctuations. A higher biodiversity effect

423 (larger $\left.z_{P}\right)$ increases both mean animal-dependent production and its stability, as well as

424 yield per area.

425

426

Net effects of fragmentation on crop production

427 Fragmentation has a dual effect on animal-dependent crop production. On one hand, 428 aggregation of seminatural fragments decreases pollination by lowering LPP, which in 429 turn reduces the pollinators' carrying capacity. On the other hand, aggregation benefits 430 biodiversity (Fig. S5), which in turn increases pollinators' biomass and animal 431 pollination. The net effect of fragmentation on animal-dependent production depends on 432 the distance-decay of ecosystem service flow $\left(d_{m}\right)$ and the proportion of seminatural 433 habitat remaining. When the decay distance is low (Fig. 5, first row), fragmentation 434 effects tend to be positive for mean animal-dependent production and yield per area 435 because the fraction of crop land within reach from non-crop land areas is higher. Yet, 436 the stability of animal-dependent production decreases due to the lower biodiversity in 437 fragmented landscapes, except at high fractions of seminatural habitat where the impact 438 of fragmentation is minimum. Conversely, when the decay distance is high, seminatural 
439 fragments are perceived as more connected and animal-dependent production is not

440 limited by space. In this case, fragmentation becomes irrelevant, or even negative, due to

441 the lower biodiversity in fragmented landscapes (Fig. 5, last row).

442

443

\section{Discussion}

445 Our analysis reveals a variety of effects of land-use change on biodiversity and crop 446 production. Using a mean-field approximation, our model suggests that (i) the full 447 complexity of the fragmentation-induced spatial effects on animal-dependent crop 448 production is captured by one factor - the Landscape Pollination Potential of the 449 remaining seminatural land (LPP) - which determines the mean and stability of animal450 dependent production; (ii) fragmentation reduces biodiversity and increases LPP, thus impacting animal-dependent production in opposite directions; and (iii) the net effects of fragmentation on animal-dependent production depend on the strength of pollinators' spillover to crop land, the proportion of seminatural habitat remaining, and the degree to

454 which crops depend on animal pollination.

456 The loss of seminatural land has contrasting effects on agricultural landscapes: 457 biodiversity decreases, animal-independent crop production increases, while animal458 dependent crop production is maximized at intermediate fractions of seminatural habitat. 459 But fragmentation can modify these relationships in two ways. First, land-use change can 460 produce multiple patterns of aggregation of seminatural habitat fragments. These 461 patterns, combined with the strength of the spillover of pollinators to crop land, determine 462 the Landscape Pollination Potential of seminatural land, which is one main driver of food 463 production in animal-dependent agriculture. The second type of effects are mediated by 
464 biodiversity, as the level of aggregation of seminatural habitat affects the pollinator

465 richness. Such purely spatial and biodiversity-mediated effects modify the carrying

466 capacities of pollinators, which ultimately determine animal-dependent crop production.

467 The mean-field approximation shows that the effects of space on animal-dependent

468 production can be interpreted in the same terms as varying the pollinator's carrying

469 capacity in the non-spatial model, i.e. a lower LPP reduces the pollinator's carrying

470 capacity and the provision of animal-dependent production.

471

472 Our results suggest that understanding the factors that affect Landscape Pollinator

473 Potential is a fundamental step towards food security in animal-dependent agriculture. If

474 no restrictions exist in the flow of pollinators to crop land, LPP is maximum and the

475 spatial structure of land-use change does not affect crop dynamics. In this situation,

476 seminatural fragments are perceived as more connected and the provision and stability of

477 animal-dependent production is not conditioned by the spatial configuration, i.e. spatial

478 and non-spatial models converge. However, agricultural landscapes are fragmented to

479 some extent and the foraging ranges of most organisms are local (Darvill et al. 2004;

480 Zurbuchen et al. 2010; Geib et al. 2015), which produces higher aggregation and weaker

481 spillover effects, thus reducing LPP. Such reductions in LPP affect crop production by (i)

482 decreasing mean animal-dependent production and total yield per area, and (ii) decreasing

483 the stability of animal-dependent production along the seminatural habitat gradient.

484 Because LPP can have important implications for crop production, it would be interesting

485 to operationalize this metric in empirical studies and landscape management. The

486 estimation of LPP in real farming systems would require data on the aggregation of

487 seminatural habitat, and on the spillover of pollinators to adjacent crops. The former can

488 be obtained with GIS processing of aerial pictures or satellite images. For the latter, 
489 information on foraging distances of existing pollinator species (this comes from 490 ecological censuses) combined with experimental studies could be used to reveal species'

491 foraging patterns and how the flow of pollinators to adjacent crop land decays with 492 distance (examples of this type of studies are Ries et al. 2004; Rand et al. 2006; Ricketts 493 et al. 2008). This information will be useful to design agricultural landscapes for high 494 LPP. Although measuring LPP in empirical studies demands more data than simple, 495 traditional fragmentation metrics, this investment is worthy as LPP can be a better 496 predictor of crop production.

497

498 Producing food requires land, and increasing the land devoted to farming reduces the land 499 devoted to biodiversity conservation. This and other recent empirical studies show that 500 pollinator diversity can increase food production (Catarino et al. 2019; Dainese et al. 501 2019; Woodcock et al. 2019), and lead to lower variability in agricultural productivity.

502 This is relevant in the global change context, as biodiversity can stabilize animal503 dependent crop production by providing an insurance against environmental fluctuations, 504 which are predicted to intensify under global change (Giorgi et al. 2001; Saltz et al. 2006; 505 Fischer et al. 2013). The response of biodiversity to land-use change depends on the 506 amount and the spatial structure of seminatural habitat. For example, although the effects 507 of fragmentation on biodiversity are stronger at low-intermediate fractions of seminatural 508 habitat - typical of intensive farming systems -, aggregation favours biodiversity within 509 seminatural habitat fragments. The stabilizing effect of biodiversity and its role in food 510 security is increasingly supported, even at crop levels (Renard \& Tilman 2019). Our 511 results add to this view and point to biodiversity conservation as one key policy to achieve 512 food security. 
514 Our findings are consistent with previous studies that found non-linear effects of 515 fragmentation on ecosystem services (Keitt 2009; Mitchell et al. 2015), and provide a

516 theoretical basis of the effects of fragmentation on the stability of animal-dependent crop 517 production. Fragmentation has a dual effect on animal-dependent production. On one 518 hand, aggregation decreases animal-dependent production by reducing the Landscape

519 Pollination Potential. On the other hand, aggregation increases animal-dependent 520 production by maintaining higher biodiversity, especially when the proportion of 521 seminatural habitat within the agricultural landscape is medium or low. The net effects of 522 aggregation on animal-dependent crop production depend on the strength of spillover 523 effects. These results have management implications (e.g. land sharing-sparing debate;

524 Fischer et al. 2014; Grass et al. 2019), as the goals of different landscape managers can 525 be conditioned by the way that natural land is converted into crops. For example, 526 maintaining a large number of seminatural fragments may be a better strategy at multiple 527 spatial scales than maintaining a few large fragments when pollinator flow to crop land 528 is low. Yet, this strategy may increase the temporal variability of animal-dependent 529 production at low-intermediate proportions of seminatural habitat, reflecting a trade-off 530 between ecosystem service mean and stability. Conversely, larger fragments of 531 seminatural habitat have higher pollinator diversity when the fraction of seminatural 532 habitat is low or intermediate, and higher biodiversity can stabilize animal-dependent 533 production. These results agree with recent claims that the land sharing-sparing 534 dichotomy lends itself to overly simplistic policy prescriptions (Kremen 2015), and 535 suggest that management decisions for food security should consider factors such as 536 pollinators' spillover, the amount and spatial aggregation of seminatural habitat and the

537 animal pollination-dependence of crops. Our results also provide recommendations for 538 landscapes with both animal-independent and -dependent crops. In such cases, for a given 
539 proportion of seminatural habitat, management should maximize the Landscape

540 Pollination Potential while preserving pollination diversity, favouring mean crop

541 production and its stability. This could be achieved by increasing fragmentation of semi-

542 natural habitat in the vicinity of animal-dependent crops, but without making semi-natural

543 habitat patches too small so that biodiversity is not negatively affected. Animal-

544 independent production only depends on how much seminatural habitat there is, and is

545 not affected by fragmentation because it does not depend on animal pollinators and

546 seminatural habitat.

547

548 Aside from Landscape Pollination Potential (see above), what type of empirical data

549 could be used to calibrate key parameters of the model? Carrying capacities of pollinators

550 and wild plants can be approximated from species biomass and ecological censuses of

551 species numbers (Appendix S1), yet this assumes that communities are saturated. On the

552 other hand, animal pollination-dependencies of the large majority of crops is available

553 from pollinator exclusion experiments (e.g. Klein et al. 2007). Pollinator spillover

554 depends on the distance-decay function, and its parameters values require data on

555 pollinator movement patterns (distance, range), which can be obtained via experiments

556 and observational studies (e.g. tracking of 'marked' pollinator individuals with remote

557 devices; e.g. Ratnayake et al. 2021). Finally, experimental studies provide information to

558 calibrate biodiversity estimates in fragmented landscapes (SFAR function; Appendix S1),

559 as well as the effect of pollinator diversity on animal-dependent crop production (Liang

560 et al. 2016; O’Connor et al. 2017).

561

562 Our model has several limitations. First, our model focuses on intensive farming systems,

563 where crop land does not host important biodiversity levels; other types of agriculture - 
564 e.g. organic farming - allow moderate levels biodiversity to thrive within crop land, and 565 can modify the results reported here (Clough et al. 2011). The model does not consider

566 fine-scale seminatural patches (e.g. wildflower strips, hedgerows) that might support high

567 pollinator diversity by providing complementary resources within a short range from 568 crops, nor it considers habitat quality differences within seminatural fragments; although

569 the latter can affect the abundance and composition of pollinators, it would not 570 qualitatively affect the positive effect of pollinator diversity on animal-dependent 571 production. Also, the observation that biodiversity loss has either none (stability) or 572 positive (mean) effects on animal-independent crop production may change if organisms 573 responsible for other services, e.g. pest control, are included. Besides, although 574 seminatural habitat had no effect on the stability of animal-independent production, this 575 may change if environmental stochasticity of crops increases with decreasing amounts of 576 seminatural habitat, as suggested by studies linking seminatural habitat to climate 577 regulation, natural hazard regulation and water flow regulation services (Harrison et al. 578 2010). In addition, negative perturbations larger than the ones considered in our model 579 may be possible; although these so-called black-swan events are rare (e.g. they affect $\sim 3 \%$ 580 of insect populations; Anderson et al. 2017), they could heavily decrease pollinator 581 diversity, with negative impacts on animal-dependent crop production. Differences in 582 pollination efficiency may affect LPP and could be captured using functional group 583 analysis (Mayfield et al. 2019); yet, the positive diversity-function relationship still holds 584 even considering such differences (Woodcock et al. 2019). Also, differences in flight 585 ability and range across pollinators influence pollinator diversity within agricultural 586 landscapes (e.g. InVEST Crop pollination model, Lonsdorf et al. 2009), and this may in 587 turn affect LPP, through its effects on pollinator spillover, and the provision of animal588 dependent production. Therefore, differences in movement/flight patterns of pollinators 
589 should be considered in future extensions of the model, e.g. large bees such as Bombus 590 species are powerful long-distance pollinators, whereas smaller bees forage locally (e.g.

591 Lasioglossum, Halictus). Finally, our model focuses on wild central-place pollinators (i.e.

592 all types of wild bees, including bumble bees and solitary bees), whose presence and 593 abundance directly depend on seminatural habitat. Non-bee pollinators are excluded as 594 they have diverse nesting habits (e.g. many flies lack central nest locations, and others 595 depend on floral resources only during adult life). However, non-bee pollinators respond 596 less negatively to land-use changes (Rader et al. 2016), and their role in stabilizing 597 animal-dependent production is important in the event of bee declines. Honey bee 598 colonies are used to substitute wild pollinators, yet, with a few exceptions (e.g. honeybees 599 complement and sometimes efficiently pollinate crops of the family Cucurbitaceae o 600 Solanacea; Macias-Macias et al. 2009), the pollination services of wild pollinators cannot 601 be compensated by managed bees because (1) pollinator-dependent crop land grows more 602 rapidly than the stock of honey bee colonies (Lindström et al. 2016), (2) wild insects 603 generally pollinate crops more efficiently than honeybees (Garibaldi et al. 2013), and (3) 604 honeybees may depress wild pollinator densities (Winfree et al. 2007). Wild central-place 605 foragers thus remain a fundamental group of crop pollinators in agriculturally-dominated 606 landscapes (Potts 2016).

607

608 Ensuring stable food supplies is a challenge that may require multiple solutions. Policies 609 to increase production, changing diets, irrigation, crop diversity, and tolerance of crops 610 to drought, are proposed as stability-enhancing solutions (Rosenzweig \& Parry 1994; 611 Lobell et al. 2008; Godfray \& Garnett 2014; Bailey et al. 2015; Renard \& Tilman 2019).

612 By addressing multiple drivers of crop production in spatially-explicit agroecosystems, 613 our study provides a theoretical basis of the effects of fragmentation on the mean and 
614 stability of animal-dependent crop production, with strong consequences for food 615 production and food security. These results are highly relevant in the global change 616 context, and given the worldwide trends in agriculture, which shifts towards more 617 pollinator-dependent crops.

618 


\section{Acknowledgments}

620 DM was funded by the European Union and Institut National de Recherche pour 621 l'Agriculture, l'Alimentation et l'Environnement (INRAE) in the framework of the 622 Marie-Curie FP7 COFUND People Program, through the award of an 623 AgreenSkills/AgreenSkills+ fellowship, and by and the FRAGCLIM Consolidator Grant, 624 funded by the European Research Council under the European Union's Horizon 2020 625 research and innovation programme (grant agreement number 726176). This work was 626 supported by the TULIP Laboratory of Excellence (ANR-10-LABX-41) and by the 627 BIOSTASES Advanced Grant funded by the European Research Council under the 628 European Union's Horizon 2020 research and innovation program (grant agreement no. 629 666971). We also thank three anonymous referees for their insightful comments.

630

631 Author contributions

632 D.M., B.H. and M.L. conceived the original idea and designed the research. D.M. and 633 B.H. designed the model, with help from M.L. and C.M. D.M. and B.H. performed the 634 analysis. D.M. wrote the first draft of the manuscript, all authors contributed to revisions. 635

636 Data availability statement

637 Data available from the Dryad Digital

638 Repository: https://doi.org/10.5061/dryad.8sf7m0cn8 (Montoya et al., 2021).

639

640 
643 Aizen, M. A., Garibaldi, L. A., Cunningham, S. A. \& Klein, A. M. (2009). How much

644 does agriculture depend on pollinators? Lessons from long-term trends in crop 645 production. Annals of Botany, 103, 1579-1588.

646

647 Anderson, S. C., Branch, T. A., Cooper, A. B. \& Dulvy, N. K. (2017). Black-swan events 648 in animal populations. Proceedings of the National Academy of Sciences USA, 114, 32526493257.

650

651 Bailey, R., Benton, T.G., Challinor, A., Elliott, J., Gustafson, D., Hiller, B., Jones, A., 652 Jahn, M., Kent, C., Lewis, K., Meaacham, T., Rivington, M., Robson, D., Tiffin, R. \& 653 Wuebbles, D.J. (2015). Extreme Weather and Resilience of the Global Food System. 654 Final Project Report from the UK-US Task force on Extreme Weather and Global Food 655 System Resilience. In: The Global Food Security Programme. 656 https://www.foodsecurity.ac.uk/publications/archive/page/4.

657

658 Braat, L. \& ten Brink, P. (2008). The Cost of Policy Inaction: The case of not meeting 659 the 2010 biodiversity target. Wageningen, Alterra, Alterra-rapport 1718.

660

661 Breeze, T.D., Vaissière, B.E., Bommarco, R., Petanidou, T., Seraphides, N., Kozák, L., 662 Scheper, J., Biesmeijer, J.C., Kleijn, D., Gyldenkærne, S., Moretti, M., Holzschuh, A., 663 Steffan-Dewenter, I., Stout, J.C., Pärtel, M., Zobel, M. \& Potts, S. (2014). Agricultural 664 policies exacerbate honeybee pollination service supply-demand mismatches across 665 Europe. PLoS ONE, 9, e82996. 
667 Brosi, B. J., Armsworth, P. R. \& Daily, G. C. (2008). Optimal design of agricultural 668 landscapes for pollination services. Conservation Letters, 1, 27-36.

669

670 Catarino, R., Bretagnolle, V., Perrot, T., Vialloux, F. \& Gaba, S. (2019). Bee pollination 671 outperforms pesticides for oilseed crop production and profitability. Proceedings of the 672 Royal Society London B, 286, 20191550.

673

674 Clough, Y., Barkmann, J., Juhrbandt, J., Kessler, M., Wanger, T.C., Anshary, A., 675 Buchori, D., Cicuzza, D., Darras, K., Putra, D.D., Erasmi, S., Pitopang, R., Schmidt, R., 676 Schulze, C.H., Seidel, D., Steffan-Dewenter, I., Stenchly, K., Vidal, S., Weist, M., 677 Wielgoss, A.C. \& Tscharntke, T. (2011). Combining high biodiversity with high yields 678 in tropical agroforests. Proceedings of the National Academy of Sciences USA, 108, $6798311-8316$.

680

681 Dainese, M. et al. (2019). A global synthesis reveals biodiversity-mediated benefits for 682 crop production. Science Advances, 5, eaax0121.

683

684 Darvill, B., Knight, M. E. \& Goulson, D. (2004). Use of genetic markers to quantify 685 bumblebee foraging range and nest density. Oikos, 107, 471478.

686

687 Deguines, N., Jono, C., Baude, M., Henry, M., Julliard, R. \& Fontaine, C. (2014). Large688 scale trade-off between agricultural intensification and crop pollination services. 689 Frontiers in Ecology \& Environment, 12, 212-217.

690 
691 Fahrig, L. et al. Is habitat fragmentation bad for biodiversity? (2018). Biological 692 Conservation, 230, 179-186.

693

694 Farwig, N., Bailey, D., Bochud, E., Herrmann, J.D., Kindler, E., Reusser, N., Schüepp, 695 C. \& Schmidt-Entling, M.H. (2009). Isolation from forest reduces pollination, seed 696 predation and insect scavenging in Swiss farmland. Landscape Ecology, 24, 919-27.

697

698 Fischer, E. M., Beyerle, U. \& Knutti, R. (2013). Robust spatially aggregated projections 699 of climate extremes. Nature Climate Change, 3, 1033-8.

700

701 Fischer, J., Abson, D. J., Butsic, V. Chappell, M. J., Ekroos, J., Hanspach, J., Kuemmerle, 702 T., Smith, H.G. \& von Werden, H. (2014). Land sparing versus land sharing: moving 703 forward. Conservation Letters, 7, 149-157.

704

705 Fletcher, R. J. et al. Is habitat fragmentation good for biodiversity? (2018). Biological 706 Conservation, 226, 9-15.

707

708 Garibaldi, L.A., Aizen, M. A., Klein, A. M., Cunningham, S. A. \& Harder, L. D. (2011a).

709 Global growth and stability of agricultural yield decrease with pollinator dependence.

710 Proceedings of the National Academy of Sciences USA, 108, 5909-5914.

711

712 Garibaldi, L.A. et al. (2011b). Stability of pollination services decreases with isolation 713 from natural areas despite honey bee visits. Ecology Letters, 14, 1062-1072. 
715 Garibaldi, L. A. et al. (2013). Wild pollinators enhance fruit set of crops regardless of 716 honey bee abundance. Science, 339, 1608-1611.

717

718 Garibaldi, L.A., Carvalheiro, L.G., Leonhardt, S.D., Aizen, M.A., Blaauw, B.R., Isaacs,

719 R., Kuhlmann, M., Kleijn, D., Klein, A.M., Kremen, C., Morandin, L., Scheper, J. \& 720 Winfree, R. (2014). From research to action: enhancing crop yield through wild 721 pollinators. Frontiers in Ecology \& Environment, 12, 439-447.

722

723 Gill, R.J., Baldock, K.C.R., Brown, M.J.F., Cresswell, J.E., Dicks, L.V., Fountain, M.T. 724 et al. (2016). Protecting an ecosystem service: Approaches to understanding and 725 mitigating threats to wild insect pollinators. Advances in Ecological Research, 54, 135726206.

727

728 Geib, J. C., J. P. Strange \& Galenj, C. (2015). Bumble bee nest abundance, foraging 729 distance, and host-plant reproduction: implications for management and conservation. 730 Ecological Applications, 25, 768-778.

731

732 Giorgi, F., Hewitson, B., Christensen, J.H., Hulme, M., Von Storch, H., Whetton, P., 733 Jones, R., Mearns, L.O. \& Fu, C. (2001). Regional climate information-evaluation and 734 projections. In: Climate change 200 the scientific basis. Contribution of working group I 735 to the third assessment report, intergovernmental panel on climate change [eds. 736 Houghton, J. et al.] Cambridge Univ. Press, Cambridge, UK, pp. 583-638 737

738 Godfray, H. C. J. \& Garnett, T. (2014). Food security and sustainable intensification. 739 Philosophical Transactions of the Royal Society B, 369, 20120273. 
741 Grass, I., Loos, J., Baensch, S., Batáry, P., Librán-Embid, F., Ficiciyan, A., Klaus, F.,

742 Riechers, M., Rosa, J., Tiede, J., Udy, K., Westphal, C., Wurz, A. \& Tscharntke, T.

743 (2019). Land-sharing/-sparing connectivity landscapes for ecosystem services and

744 biodiversity conservation. People \& Nature, 1, 262-272.

745

746 Haan, N.L., Zhang, Y. \& Landis, D.A. (2020). Predicting landscape configuration effects 747 in agricultural pest suppression. Trends in Ecology and Evolution, 35, 175-186.

748

749 Haddad, N. M. et al. (2015). Habitat fragmentation and its lasting impact on Earth's 750 ecosystems. Science Advances, 1, e1500052.

751

752 Hanski, I., Zurita, G. A., Bellocq, M. I. \& Rybicki, J. (2013). Species-fragmented area 753 relationship. Proceedings of the National Academy of Sciences USA, 110, 12715- 12720.

754

755 Harrison, P.A., Vandewalle, M., Sykes, M.T., Berry, P.M., Bugter, R., de Bello, F., Feld,

756 C.K., Grandin, U., Harrington, R., Haslett, J.R., Jongman, R.H.G., Luck, G.W., da Silva, 757 P.M., Moora, M., Settele, J., Sousa, J.P. \& Zobel, M. (2010). Identifying and prioritizing 758 services in European terrestrial and freshwater ecosystems. Biodiversity Conservation, $75919,2791-2821$.

760

761 Holland, J. N., Y. Wang, S. Shan \& DeAngelis, D. L. (2013). Consumer-resource 762 dynamics of indirect interactions in a mutualism-parasitism food web module. 763 Theoretical Ecology, 6, 475-493. 
765 Holland, J. N. (2015). Population ecology of mutualism. In: Mutualism (ed. Bronstein, 766 J.). Oxford University Press, Oxford, UK, pp 133-158.

767

768 Keitt, T. H. (2009). Habitat conversion, extinction thresholds and pollination services in 769 agroecosystems. Ecological Applications, 19, 1561-1573.

770

771 Kennedy C.M., Lonsdorf E., Neel M.C., Williams N.M., Ricketts T.H., Winfree R.,

772 Bommarco R., Brittain C., Burley A.L., Cariveau D., Carvalheiro L.G., Chacoff N.P., 773 Cunningham S.A., Danforth B.N., Dudenhöffer J.H., Elle E,. Gaines H.R., Garibaldi 774 L.A., Gratton C., Holzschuh A., Isaacs R., Javorek S.K., Jha S., Klein A.M., Krewenka 775 K., Mandelik Y., Mayfield M.M., Morandin L., Neame L.A., Otieno M., Park M., Potts 776 S.G., Rundlöf M., Saez A., Steffan-Dewenter I., Taki H., Viana B.F., Westphal C., 777 Wilson J.K., Greenleaf S.S., Kremen C. (2013). A global quantitative synthesis of local 778 and landscape effects on wild bee pollinators in agroecosystems. Ecology Letter, 16, 584779599.

780

781 Kleijn, D. et al. (2015). Delivery of crop pollination services is an insufficient argument 782 for wild pollinator conservation. Nature Communications 6, 7414.

783

784 Klein, A.-M., Vaissière, B.E. Cane, J.H., Steffan-Dewenter, I., Cunningham, S.A., 785 Kremen, C. \& Tscharntke, T. (2007). Importance of pollinators in changing landscapes 786 for world crops. Proceedings of the Royal Society B, 274, 303-313.

787

788 Kremen, C. (2015). Reframing the land-sparing/land-sharing debate for biodiversity 789 conservation. Annals of the New York Academy of Sciences, 1355. 
791 Lande, R., S. Engen \& B.-E. Saether. (2003). Stochastic population dynamics in ecology 792 and conservation. Oxford University Press, Oxford, UK.

793

794 Lefcheck, J.S., Byrnes, J.E.K., Isbell, F., Gamfeldt, L., Griffin, J.N., Eisenhauer, N., 795 Hensel, M.J.S., Hector, A., Cardinale, B.J. \& Duffy, J.E. (2015). Biodiversity enhances 796 ecosystem multifunctionality across trophic levels and habitats. Nature Communications, $7976,6936$.

798

799 Liang, J. et al. (2016). Positive biodiversity-productivity relationship predominant in 800 global forests. Science, 354, aaf8957.

801

802 Lindström, S. A. M., Herbertsson, L., Rundolf, M., Bommarco, R. \& Smith, H. G. (2016)

803 Experimental evidence that honeybees depress wild insect densities in a flowering crop. 804 Proceedings of the Royal Society London B, 283, 20161641.

805

806 Lobell, D.B., Burke, M.B., Tebaldi, C., Mastrandrea, M.D., Falcon, W.P. \& Naylor, R.L. 807 (2008). Prioritizing climate change adaptation needs for food security in 2030. Science, $808319,607-610$.

809

810 Lonsdorf, E., Kremen, C., Ricketts, T., Winfree, R., Williams, N. \& Greenleaf,S. (2009).

811 Modelling pollination services across agricultural landscapes. Annals of Botany, 103, 812 1589-1600.

813 
814 Loreau, M., Mouquet, N. \& Gonzalez, A. (2003). Biodiversity as spatial insurance in 815 heterogeneous landscapes. Proceedings of the National Academy of Sciences USA, $100,12765-12770$.

817

818 Loreau, M. \& De Mazancourt, C. (2013). Biodiversity and ecosystem stability: a synthesis of underlying mechanisms. Ecology Letters, 16, 106-115.

820

821

Macias-Macias, O., Chuc, J., Ancona-Xiu, P., Cauich, O. \& Quezada-Euán, J.J.G. (2009).

822

Contribution of native bees and Africanized honey bees (Hymenoptera:Apoidea) to

823 Solanaceae crop pollination in tropical México. Journal of Applied Entomology, 133, $824 \quad 456-465$.

825

826

Martin, E.A., Dainese, M., Clough, Y., Báldi, A., Bommarco, R., Gagic, V., Garratt, M.P.D., Holzschuh, A., Kleijn, D., Kovács-Hostyánszki, A., Marini, L., Potts, S.G.,

828 Smith, H.G., Al Hassan, D., Albrecht, M., Andersson, G.K.S., Asís, J.D., Aviron, S., 829 Balzan, M.V., Baños-Picón, L., Bartomeus, I., Batáry, P., Burel F., Caballero-López, B., 830 Concepción, E.D., Coudrain, V., Dänhardt J., Diaz, M., Diekötter, T., Dormann, C.F., 831 Duflot, R., Entling, M.H., Farwig, N., Fischer, C., Frank, T., Garibaldi, L.A., Hermann, 832 J., Herzog, F., Inclán, D., Jacot, K., Jauker, F., Jeanneret, P., Kaiser, M., Krauss, J., Le 833 Féon, V., Marshall, J., Moonen, A.C., Moreno, G., Riedinger, V., Rundlöf, M., Rusch, 834 A., Scheper, J., Schneider, G., Schüepp, C., Stutz, S., Sutter, L., Tamburini, G., Thies, C., 835 Tormos, J., Tscharntke, T., Tschumi, M., Uzman, D., Wagner, C., Zubair-Anjum, M., 836 Steffan-Dewenter, I. (2019). The interplay of landscape composition and configuration: 837 new pathways to manage functional biodiversity and agroecosystem services across 838 Europe. Ecology Letters, 22, 1083-1094. 
840 Martins, K. T., Gonzalez, A. \& Lechowicz, M. J. (2015). Pollination services are

841 mediated by bee functional diversity and landscape context. Agriculture, Ecosystems \&

842 Environment, 200, 12-20.

843

844 Matsuki, Y., Tateno, R., Shibata, M. \& Isagi, Y. (2008). Pollination efficiencies of flower-

845 visiting insects as determined by direct genetic analysis of pollen origin. American 846 Journal of Botany, 95, 925-930.

847

848 Mayfield, M.M., Bonser, S.P., Morgan, J.W., Aubin, I., McNamara, S. \& Vesk, P.A.

849 (2010). What does species richness tell us about functional trait diversity? Predictions

850 and evidence for responses of species and functional trait diversity to land-use. Global

851 Ecology and Biogeography, 19, 423-431.

852

853 Mitchell, M. G. E., Bennett, E. M. \& Gonzalez, A. (2014). Forest fragments modulate the 854 provision of multiple ecosystem services. Journal of Applied Ecology, 51, 909-18.

855

856 Mitchell, M. G. E., Bennett, E. M. \& Gonzalez, A. (2015). Strong and non-linear effects

857 of fragmentation on ecosystem service provision at multiple scales. Environmental $858 \quad$ Research Letters, 10, 094014.

859

860 Montoya, D., Haegeman, B., Gaba, S., De Mazancourt, C., Bretagnolle, V. \& Loreau, M. 861 (2019). Trade-offs in provisioning and stability of multiple ecosystem services in 862 agroecosystems. Ecological Applications, 29, e01853. 
864 Montoya, D., Gaba, S., de Mazancourt, C., Bretagnolle, V. \& Loreau, M. (2020).

865 Reconciling biodiversity conservation, food production and farmers' demand in 866 agricultural landscapes. Ecological Modelling, 416, 108889.

867

868 Montoya, D., Haegeman, B. Gaba, S. De Mazancourt, C. \& Loreau, M. (2021). Habitat 869 fragmentation and food security in crop pollination systems. Dryad Digital 870 Repository, https://doi.org/10.5061/dryad.8sf7m0cn8

871

872 O’Connor, M., Gonzalez, A. Byrnes, J.E.K., Cardinale, B.J., Duffy, J.E., Gamfeldt, L., 873 Griffin, J.N., Hooper, D., Hungate, B.A., Paquette, A., Thompson, P.L., Dee, L.E. \& 874 Dolan, K.L. (2016). A general biodiversity-function relationship is mediated by trophic 875 level. Oikos, 126, 18-31.

876

877 Potts, S.G. (2016). Safeguarding pollinators and their values to human well-being. 878 Nature, 540, 220-229.

879

880 Rader R., Bartomeus I., Garibaldi L.A., Garratt M.P., Howlett B.G., Winfree R., 881 Cunningham S.A., Mayfield M.M., Arthur A.D., Andersson G.K., Bommarco R., Brittain 882 C., Carvalheiro L.G., Chacoff N.P., Entling M.H., Foully B., Freitas B.M., Gemmill883 Herren B., Ghazoul J., Griffin S.R., Gross C.L., Herbertsson L., Herzog F., Hipólito J., 884 Jaggar S., Jauker F., Klein A.M., Kleijn D., Krishnan S., Lemos C.Q., Lindström S.A., 885 Mandelik Y., Monteiro V.M., Nelson W., Nilsson L., Pattemore D.E., Pereira Nde O., 886 Pisanty G., Potts S.G., Reemer M., Rundlöf M., Sheffield C.S., Scheper J., Schüepp C., 887 Smith H.G., Stanley D.A., Stout J.C., Szentgyörgyi H., Taki H., Vergara C.H., Viana 
888

889

890

891 R Core Team. R: A language and environment for statistical computing. (2017). R

892 Foundation for Statistical Computing, Vienna, Austria. https://www.R-project.org/.

893

894

895

896

897

898

899

900

901

902 Réchauchère, O., Bispo, A., Gabrielle, B. \& Makowski, D. (2018). Sustainable 903

904

905

906

907

908

909 Ricketts, T.H., Regetz, J., Steffan=Dewenter, I., Cunningham, S.A., Kremen, C>,

910 Bogdanski, A., Gemmill-Herren, B., Greenleaf, S.S., Klein, A.M., Mayfield, M.M.,

911 Morandin, L.A., Ochieng, A., Potts, S \& Viana, B.F. (2008). Landscape effects on crop

912 pollination services: are there general patterns? Ecology Letters, 11, 499-515. 
914 Ries, L., Fletcher, R. J. Jr, Battin, J. \& Sisk, T. D. (2004). Ecological responses to habitat

915 edges: mechanisms, models, and variability explained. Annual Review of Ecology,

916 Evolution \& Systematics, 35, 491-522.

917

918 Rosenzweig, C. \& Parry, M. L. (1994). Potential impact of climate change on world food 919 supply. Nature, 367, 133-138.

920

921 Rybicki, J., Abrego, N. \& Ovaskainen, O. (2020). Habitat fragmentation and species 922 diversity in competitive communities. Ecology Letters, 23, 506-517.

923

924 Saltz, D., Rubenstein, D. I. \& White, G. C. (2006). The impact of increased environmental 925 stochasticity due to climate change on the dynamics of Asiatic wild ass. Conservation 926 Biology, 20, 1402-1409.

927

928 Schmidhuber, J. \& Tubiello, F. N. (2007). Global food security under climate change.

929 Proceedings of the National Academy of Sciences USA, 104, 19703-19708.

930

931 Thébault, E. \& Fontaine, C. (2010). Stability of ecological communities and the 932 architecture of mutualistic and trophic networks. Science, 329, 853-856.

933

934 Tilman, D. (1999). The ecological consequences of changes in biodiversity: a search for 935 general principles. Ecology, 80, 1455-1474.

936 
937

United Nations Sustainable Development Goals (2017). http://www.un.org/

938 sustainabledevelopment/sustainable-development-goals/.

939

940 Willcox, B.K., Aizen, M.A., Cunningham, S.A., Mayfield, M.M. \& Rader, R. (2017).

941 Deconstructing pollinator community effectiveness. Current Opinion in Insect Science,

$942 \quad 21,98-104$.

943

944 Winfree, R., Williams, N. M., Dushoff, J. \& Kremen, C. (2007). Native bees provide 945 insurance against ongoing honey bee losses. Ecology Letters, 10, 1105-1113.

946

947 Winfree, R. \& Kremen, C. (2009). Are ecosystem services stabilized by differences 948 among species? A test using crop pollination. Proceedings of the Royal Society B: 949 Biological Sciences, 276, 229-237.

950

951 Woodcock, B. A. et al. (2019). Meta-analysis reveals that pollinator functional diversity 952 and abundance enhance crop pollination and yield. Nature Communications, 10, 1481.

953

954 Zurbuchen, A., Landert, L., Klaiber, J., Müller, A., Hein, S. \& Dorn, S. (2010). Maximum

955 foraging ranges in solitary bees: only few individuals have the capability to cover long 956 foraging distances. Biological Conservation, 143, 669-676. 


\section{Figures and Tables}

958

959 Table 1 | Parameters and variables of the model. An asterisk in the unit column

960 indicates that the value of that parameter depends on fragmentation.

961

962 Figure 1 | Conceptual diagram of our modelling framework. Green boxes represent

963 non-spatial components of the model, whereas blue boxes are the additions that space

964 brings to the model. Adding space allows (i) to explore a continuous gradient of land-use

965 change patterns, from completely random to highly aggregated, that encompasses a wide

966 range of fragmentation scenarios, (ii) to investigate the effects of fragmentation on

967 pollinator diversity and animal-dependent crop production, and (iii) to study how

968 variations in the strength of spillover from seminatural habitat to crop land - i.e. the

969 distance-decay of pollination flow - affects animal-dependent production. Following a

970 mean-field approximation, the Landscape Pollinator Potential (LPP) of the agricultural

971 landscape captures the full complexity of fragmentation effects on ecosystem service

972 supply that are not mediated by biodiversity. The model has some key assumptions: (i)

973 Agricultural system is intensively-managed, defined by two patch types (crop land,

974 seminatural habitat), where crops are harvested yearly; (ii) Pollinators are generalist

975 central-place foragers, similar in movement patterns; (iii) Pollinator spillover follows a

976 logistic distance-decay function; and (iv) positive relationships between pollinator

977 diversity and animal-dependent production (mean and stability). Different effects are

978 represented by different arrow colors: blue for positive, red for negative, black for neutral

979 or context-dependent. Land-use change does not affect stability of animal-independent

980 crop production (see main text), and no arrow is drawn. For further information on model

981 assumption, see Methods and Appendix S1. 
983 Figure 2 | Mean-field approximation vs Exact solution. (a) Mean animal-dependent

984 crop production. (b) Variability of animal-dependent crop production (measured as 985 Coefficient of Variation - $\mathrm{CV}$-, the inverse of stability). A range of fragmentation 986 patterns with different levels of spatial aggregation were generated for different fractions 987 of seminatural habitat. For different fractions of seminatural habitat $\omega_{s n}$, we generated

988

989

990

991

992

993

994

995

996

997

998

999

1000

1001

1002

1003

1004

1005

1006

Figure 3 | Effects of landscape composition and LPP on crop production. (A) Mean animal-dependent production, (B) Stability of animal-dependent production stability, (C) Total yield per area, (D) Mean animal-independent production, (E) Stability of animalindependent production. Ecosystem services are represented as a function of the proportion of seminatural habitat, for different LPP. LPP includes the effects of fragmentation - more specifically, the aggregation pattern of land-use change - and the distance-decay of ecosystem service flow. Parameter values: $\alpha_{\mathrm{P}}=\alpha_{\mathrm{W}}=0.9, \beta_{\mathrm{P}}=\beta_{\mathrm{W}}=$ $0.6, \beta_{\mathrm{C}}=0.01, A=10, Z_{C}=1000, \alpha_{\mathrm{C}}=1000, k_{W}=5000, \sigma_{\mathrm{P}}^{\mathrm{e}}=0.8, \sigma_{\mathrm{P}}^{\mathrm{d}}=0.1, \sigma^{\mathrm{e}}{ }_{\mathrm{C}}=0.03$, 
$\alpha_{\mathrm{C}}=1000, z_{P}=0.26, c_{P}=1, z_{S}=0.25, c_{S}=10, b=10, q=1 / 2$, Pollination dependence $=$ $50 \%$.

1009

1010 Figure 4 | Effects of biodiversity on animal-dependent crop production. Plots show the response of animal-dependent production mean and stability (panels $\mathbf{A}$ and $\mathbf{B}$ ), and yield per area (panel $\mathbf{C}$ ) - as a function of the proportion of seminatural habitat (SNH). All LPP values are contained within the shadows, whose limits are determined by the minimum and maximum values across the range of LPP (illustrated by the arrows joining $\mathrm{LPP}_{\min }$ and $\mathrm{LPP}_{\max }$ values in panel $\mathrm{B}$ ). Biodiversity can affect crop production in a twoway manner. On one hand, biodiversity influences mean animal-dependent production and yield per area by increasing the carrying capacity of pollinators $\left(k_{p}=c_{P} S^{z_{P}}\right)$. On the other hand, biodiversity impacts the stability of animal-dependent crop production both indirectly - increasing the carrying capacity of pollinators - and directly - reducing the response of animal-dependent production to environmental fluctuations $\left(\sigma_{P}^{e}=e_{P} / S^{q}\right)$.

1021 For each ecosystem service, the plots compare two scenarios: (i) a scenario where biodiversity has no effect on animal-dependent production $\left(z_{P}=0, q=0\right)$, represented by the grey shadows, versus (ii) a scenario where biodiversity has an effect on animaldependent production $\left(z_{P}=0.26, q=1 / 2\right)$ (Tilman 1999; Liang et al. 2016; O'Connor et al. 2016), represented by the light orange shadows. Parameter values: $\alpha_{\mathrm{P}}=\alpha_{\mathrm{W}}=0.9, \beta_{\mathrm{P}}=\beta_{\mathrm{W}}$ $=0.6, \beta_{\mathrm{C}}=0.01, A=10, Z_{C}=1000, \alpha_{\mathrm{C}}=1000, k_{W}=5000, \sigma_{\mathrm{P}}^{\mathrm{e}}=0.8, \sigma_{\mathrm{P}}^{\mathrm{d}}=0.1, \sigma^{\mathrm{e}}{ }_{\mathrm{C}}=0.03$, $\alpha_{C}=1000, c_{P}=1, z_{S}=0.25, c_{S}=10, b=10$, Pollination dependence $=50 \%$. represent, from left to right, mean and stability of animal-dependent production, and yield per area. Ecosystem services are plotted as a function of fragmentation for different 
1032 proportion of seminatural habitat or SNH (as opposed to Figs. 3-4). In each plot, 1033 fragmentation increases in the $\mathrm{x}$-axis from left to right. Darker lines correspond to lower 1034 fractions of seminatural habitat, which are more typical of intensive farming systems. 1035 Rows represent increasing values of pollinator spillover or decay distance $d_{m}(0.5,1,5)$. 1036 Parameter values: $\alpha_{\mathrm{P}}=\alpha_{\mathrm{W}}=0.9, \beta_{\mathrm{P}}=\beta_{\mathrm{W}}=0.6, \beta_{\mathrm{C}}=0.01, A=10, Z_{C}=1000, \alpha_{\mathrm{C}}=1000$, $1037 k_{W}=5000, \sigma_{\mathrm{P}}^{\mathrm{e}}=0.8, \sigma_{\mathrm{P}}^{\mathrm{d}}=0.1, \sigma^{\mathrm{e}}{ }_{\mathrm{C}}=0.03, \alpha_{\mathrm{C}}=1000, z_{P}=0.26, c_{P}=1, z_{S}=0.25, c_{S}=10$, $1038 b=10, q=1 / 2$, Pollination dependence $=50 \%$. 
Table 1 | Parameters and variables of the model.

\begin{tabular}{|c|c|c|c|}
\hline $\begin{array}{l}\text { Parameters } \\
\text { \& Variables }\end{array}$ & Definition & Dimensions & Units \\
\hline \multicolumn{4}{|l|}{ Parameters } \\
\hline$\alpha_{P}$ & Maximum growth rate of pollinators & dimensionless & 0.9 \\
\hline$\alpha_{W}$ & Maximum growth rate of semi-natural plants & dimensionless & 0.9 \\
\hline$\alpha_{C}$ & Maximum crop production derived from pollinator interactions & 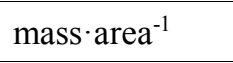 & 1000 \\
\hline$\beta_{P}$ & Half-saturation constant of pollinators & mass & 0.6 \\
\hline$\beta_{W}$ & Half-saturation constant of 'wild' plants & mass $\cdot$ area $^{-1}$ & 0.6 \\
\hline$\beta_{C}$ & Half-saturation constant of crop plants to pollinators & mass $\cdot$ area $^{-1}$ & 0.01 \\
\hline$k_{P}$ & Carrying capacity of pollinators per unit area & mass $\cdot \operatorname{area}^{-1}$ & $*$ \\
\hline$k_{W}$ & Carrying capacity of semi-natural plants per unit area & mass $\cdot$ area $^{-1}$ & 5000 \\
\hline$A$ & Total landscape area & area & 10 \\
\hline$n^{2}$ & Number of cells in the simulated landscape & dimensionless & 625 \\
\hline$A_{1}$ & Area of a single cell & area & 1 \\
\hline$\omega_{s n}$ & Proportion of semi-natural habitat & dimensionless & $\{0-1\}$ \\
\hline$w$ & Aggregation parameter of the fragmentation pattern generation algorithm & dimensionless & $\{0,5\}$ \\
\hline$Z_{C}$ & Crop production independent of animal pollinators & mass $\cdot \operatorname{area}^{-1}$ & $\{0,1000,4000\}$ \\
\hline$d_{m}$ & Distance over which the pollination flow equals one half of its initial value & distance & $\{0.1-10\}$ \\
\hline$\Delta d$ & $\begin{array}{l}\text { Distance over which the pollination flow decreases from } 90 \% \text { to } 10 \% \text { of its } \\
\text { initial value }\end{array}$ & distance & $\{0.1-10\}$ \\
\hline$c_{s}$ & Prefactor of the SAR function & dimensionless & $*$ \\
\hline$z_{s}$ & Exponent of the SAR function & dimensionless & 0.25 \\
\hline
\end{tabular}




\begin{tabular}{|c|c|c|c|}
\hline$c_{P}$ & Parameters of the power law ( $k_{P}$ dependence on $S$ ) & mass $\cdot \operatorname{area}^{-1}$ & 1 \\
\hline$z_{P}$ & Parameters of the power law ( $k_{P}$ dependence on $S$ ) & dimensionless & $\{0,0.26,0.5\}$ \\
\hline$\sigma_{P}^{e}$ & Environmental standard deviation of pollinators & dimensionless & 0.8 \\
\hline$\sigma^{e} W$ & Environmental standard deviation of 'wild' plants & dimensionless & 0.02 \\
\hline$\sigma^{e}{ }_{C}$ & Environmental standard deviation of crop production & dimensionless & 0.03 \\
\hline$\sigma^{d} P$ & Demographic standard deviation of pollinators & $\operatorname{mass}^{-1 / 2}$ & 0.1 \\
\hline$\sigma^{d} W$ & Demographic standard deviation of semi-natural plants & mass $^{-1 / 2}$ & 0.5 \\
\hline $\begin{array}{l}u_{P}^{e}, u_{P}^{d} \\
u_{W}^{e}, u^{d} \\
u_{C}^{e}\end{array}$ & $\begin{array}{l}\text { Gaussian random variables with zero mean and unit variance. } u^{e}= \\
\text { environmental, } u^{d}=\text { demographic } \\
P=\text { pollinators; } W=\text { 'wild' plants; } C=\text { crop plants }\end{array}$ & dimensionless & $\begin{array}{l}\text { Gaussian random } \\
\text { variables with zero mean } \\
\text { and unit variance }\end{array}$ \\
\hline$S$ & Number of pollinator species & dimensionless & $*$ \\
\hline$b$ & Parameter modulating the effect of the metapopulation capacity (SFAR) & dimensionless & $\{10,20,50\}$ \\
\hline $1 / \delta$ & Dispersal distance to calculate metapopulation capacity (SFAR) & dimensionless & $\{1-10\}$ \\
\hline$\lambda_{M}$ & Metapopulation capacity (SFAR) & dimensionless & $*$ \\
\hline \multicolumn{4}{|l|}{ Variables } \\
\hline$C_{k}(t)$ & Biomass of crop plants (crop production) in cell $k$ & mass & * \\
\hline$W_{k}(t)$ & Biomass of semi-natural or 'wild' plants in cell $k$ & mass & $*$ \\
\hline$P_{k}(t)$ & Biomass of pollinators in cell $k$ & mass & $*$ \\
\hline$r_{P, k}(\mathrm{t})$ & Intrinsic growth rate of pollinators in cell $k$ & dimensionless & $*$ \\
\hline$r_{W, k}(\mathrm{t})$ & Intrinsic growth rate of 'wild' plants in cell $k$ & dimensionless & * \\
\hline$r_{C, k}(\mathrm{t})$ & Crop production derived from pollinator interactions & mass $\cdot \operatorname{area}^{-1}$ & $*$ \\
\hline \multicolumn{4}{|l|}{ Other } \\
\hline$d_{k l}$ & Distance between cells $k$ and $l$ & distance & $*$ \\
\hline$\varepsilon k l$ & Distance decay function of ecosystem service flow & dimensionless & $*$ \\
\hline
\end{tabular}




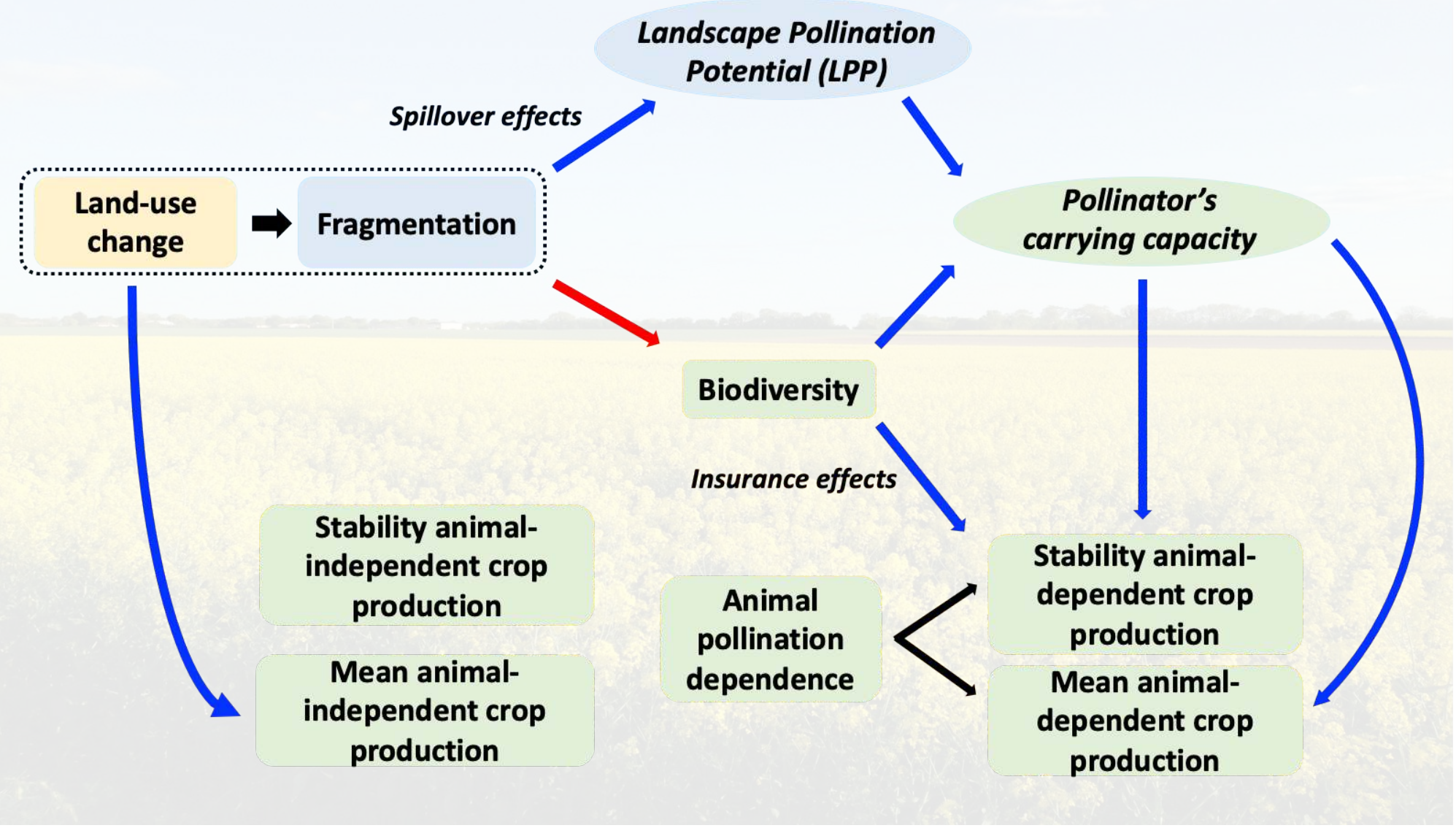


Figure 2

\section{Animal-dependent crop production}

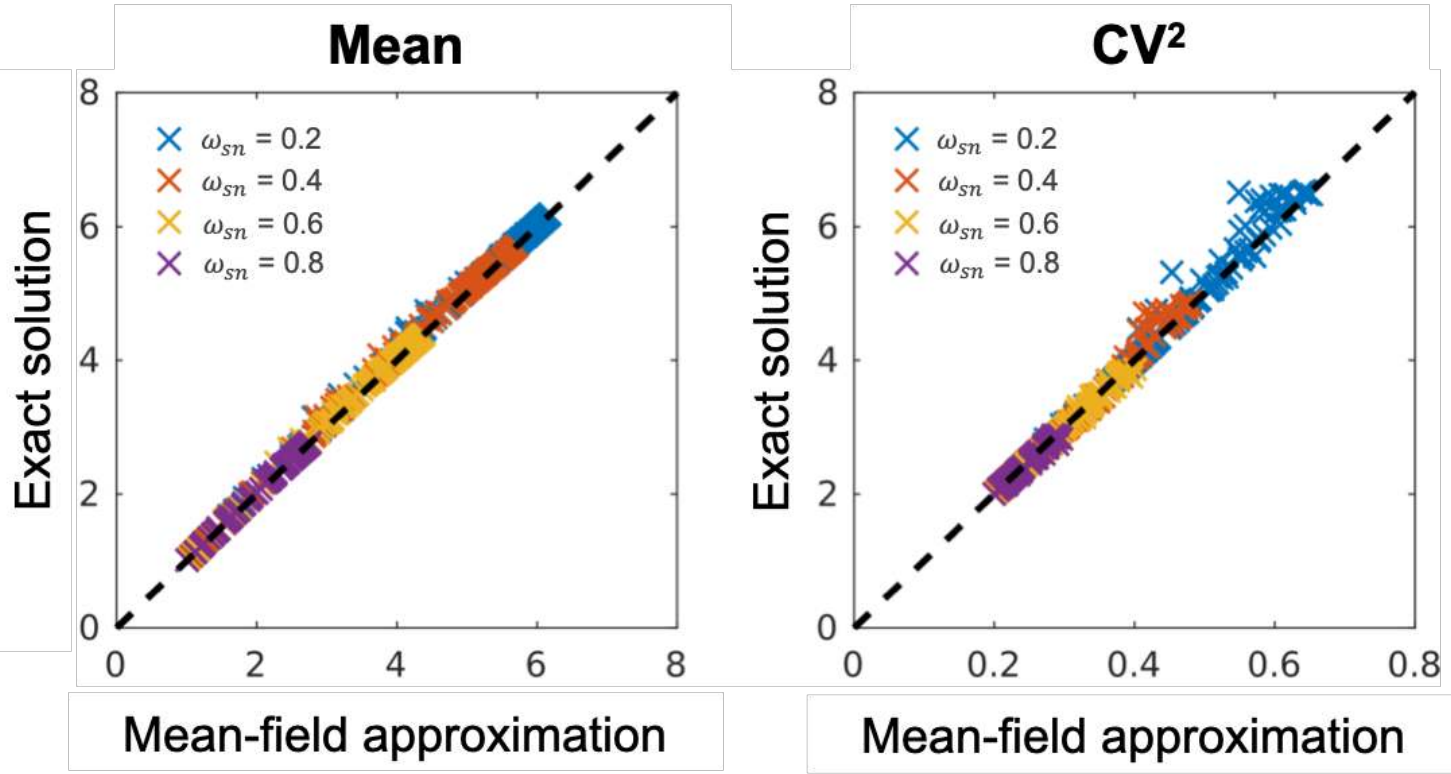

1046 
1048
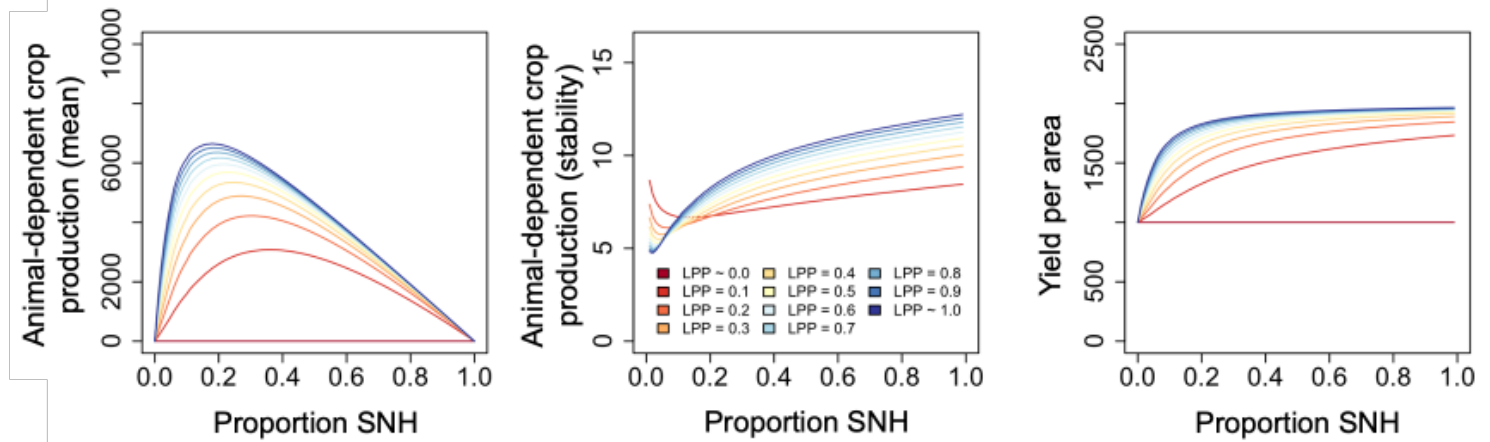

1049
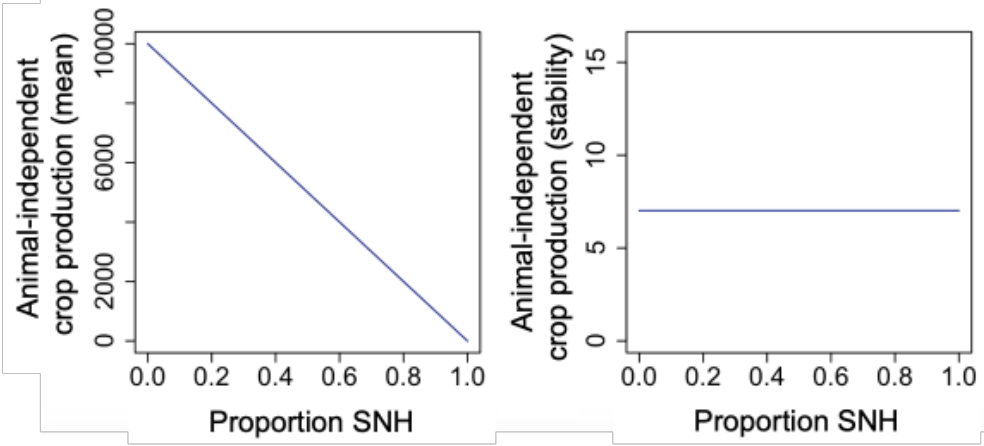

1050 
$1051 \quad$ Figure 4

1052

1053

1054
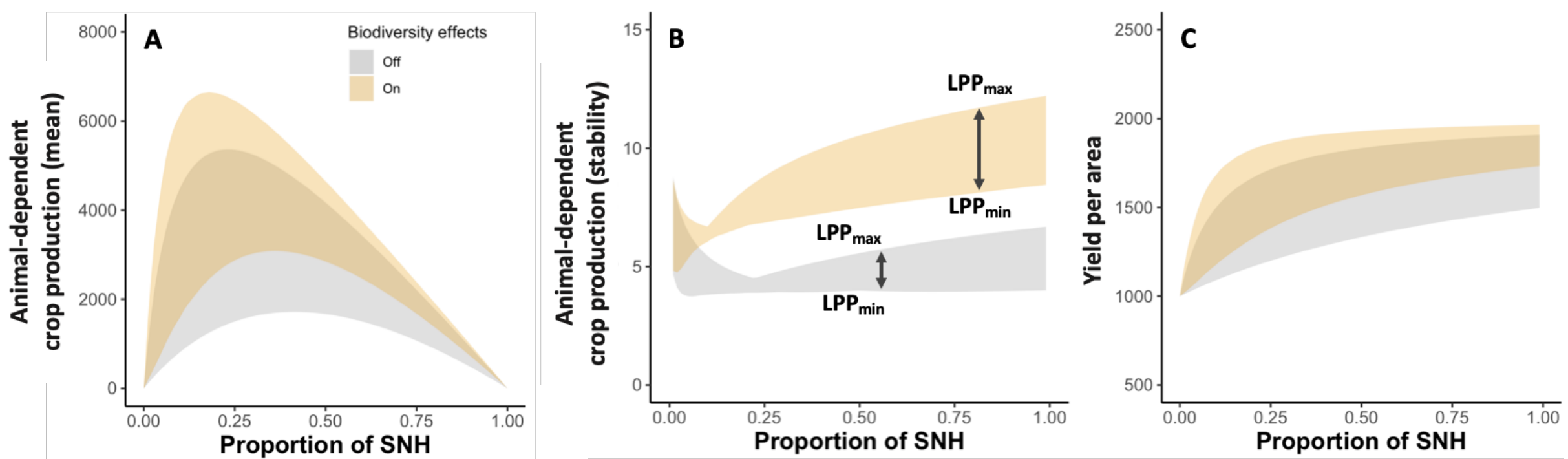

1055

1056 
1058

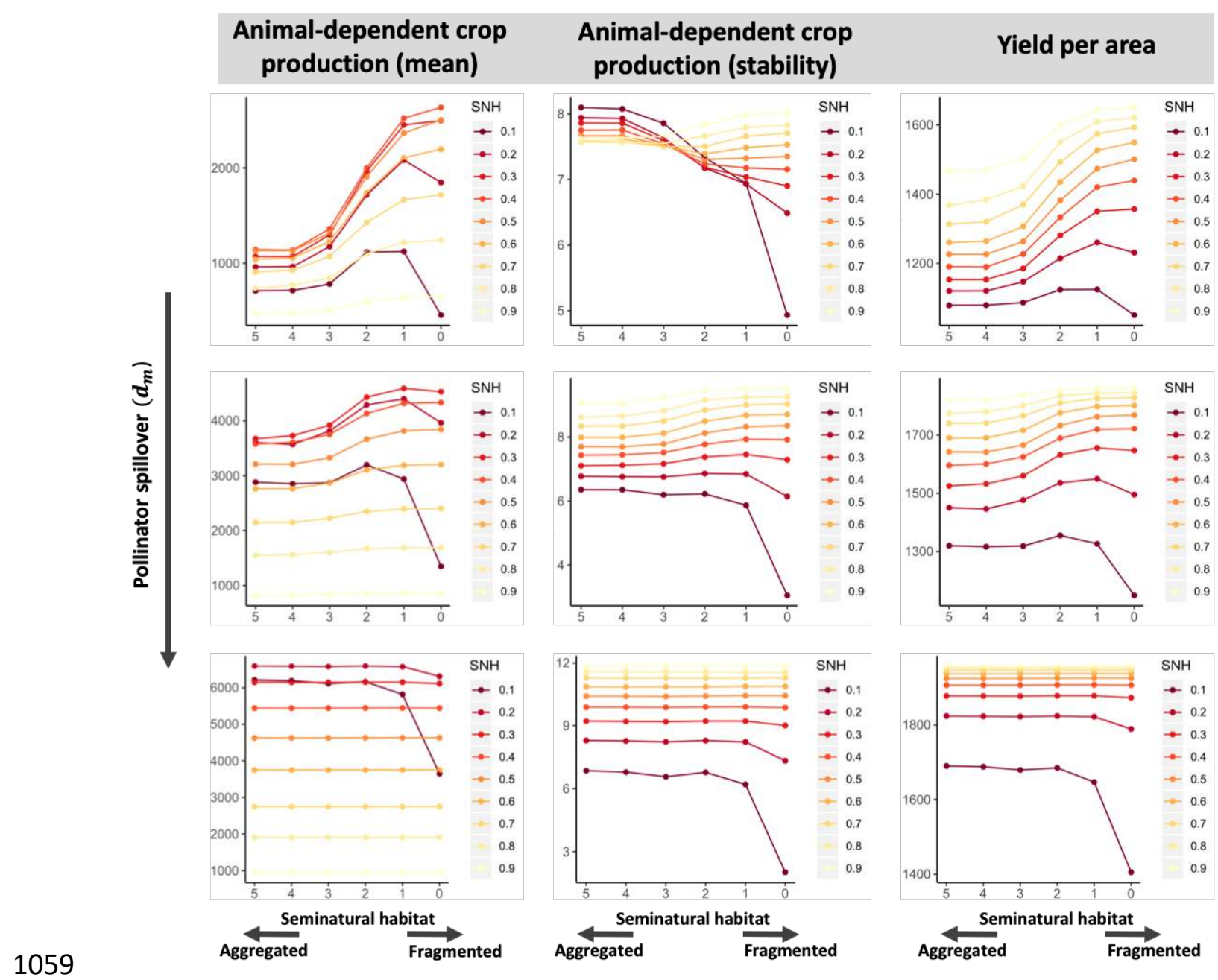

